\title{
CONVERSAS: HISTÓRIA \\ DO CURRÍCULO E DA
}

HISTÓRIA DA EDUCAÇÃO

Douglas Tomácio Lopes Monteiro ${ }^{1}$

CARVALHO, Fábio Garcez de; FERREIRA, Marcia Serra; XAVIER, Libania. História do Currículo e História da Educação: interfaces e diálogos (orgs). Rio de Janeiro: Quarter: Faperj, 2013.380p.

1 Douglas Tomácio Lopes Monteiro, Mestre em educação pela Universidade Federal de Juiz de Fora (UFJF), é especialista em docência e gestão do ensino superior, pela Pontifícia Universidade Católica de Minas Gerais (PUCMG), graduado em pedagogia pela Universidade do Estado de Minas Gerais (UEMG) e em história, bacharelado e licenciatura, também pela PUC-MG.

E-mail: dtlmeduc@gmail.com 



\section{ESPAÇOS TRANSFRONTEIRIÇOS EM DIÁLOGO: CONVERSAS \\ E ENTRECRUZAMENTOS \\ NOS CAMPOS DA HISTÓRIA \\ DO CURRÍCULO E DA \\ HISTÓRIA DA EDUCAÇÃO}

Fruto de pesquisas conjuntas do Núcleo de Estudos de Currículo (NEC/UFRJ) e Programa de Estudos e Documentação, Educação e Sociedade (Proedes/UFRJ), ambos alocados no Programa de Pós-Graduação em Educação da Universidade Federal do Rio de Janeiro (PPGE/UFRJ), o livro "História do Currículo e História da Educação: interfaces e diálogos" nasce com o claro intuito de divulgar os estudos históricos por esses grupos desenvolvidos, extrapolando, em paráfrase à Sílvia Alícia Martínez, as reflexôes geralmente circunscritas nos intramuros da academia.

Embora dividida em três partes, quais sejam: "Tempos, culturas e discursos"; "Currículos, disciplinas e materiais didáticos"; e, por fim, "Professores, intelectuais e instituiçôes", a supracitada obra, esforço conjunto de variados autores sob a organizaçáo de Fábio Carvalho, Marcia Ferreira e Libania Xavier, estabelece um prolífico diálogo entre as partes que a constituem, deixando-nos claro o caráter quase que absolutamente didático da divisão apresentada.

Feitura de distintas mãos, pautadas em interesses muitas vezes comuns - ainda que com riqueza abarquem suas especificidades -, os autores dos 15 textos no livro coletados, reconhecendo o transfronteiriço espaço entre História da Educaçáo e História do Currículo, permeado de entrecruzamentos e diálogos que em suas abordagens se fazem

Educ. foco, Juiz de Fora, v. 20 , n. 2 , jul. 2015 / out. 2015 
sentir, acabam por ratificar o caminho pelo qual há algum tempo perpassamos na investigação científico-acadêmica, caminho este de renovação teórica, metodológica e disciplinar, que nos oferta, em grande amplitude, questionamentos acerca das interfaces do conhecimento, indo de encontro às inférteis clivagens. Assim, basilados por distintas fontes, desde as primárias às secundárias, e tendo em vista as referidas interfaces dos assinalados campos, os trabalhos da obra se lançam a desafios variados no que tange à discussão acerca da produção do conhecimento, bem como de sua divulgação por meio dos currículos e disciplinas escolares e acadêmicas, isso em um exercício constante de identificar a imbricada conexão entre esse conhecimento e os saberes científicos e pedagógicos. Concomitantemente, assinalam uma abordagem circunscrita aos professores, à formação profissional destes e suas condiçôes de trabalho, lançando luz, inclusive, sobre a importante ação do professorado enquanto categoria efetiva na produção de conhecimento e reflexóes sobre a educação.

Tendo traçado de modo mais conciso as similitudes que permeiam a obra e que, de algum modo, proeminentemente caracterizam o diálogo entres os autores, neste momento me deterei mais especificamente aos eixos norteadores de cada uma das três seçóes que a compartimentam.

Em sua primeira parte, em voga está a análise das categorias "tempo", "cultura" e "discurso", as quais se fazem marcantes nos diálogos estabelecidos entre a História da Educação e História do Currículo e a historiografia hodierna. Vale destacar que as categorias elencadas são contempladas pelos autores a partir, principalmente, da abordagem culturalista. Estes, nessa perspectiva que suportada é pelas teorias do Discurso e da História, em suas postulaçóes advogam outras possibilidades de produção do conhecimento histórico.

Assim, sob o viés pós-fundacional do Discurso, o leitor é e "historicidade"; especialmente quando referentes à história das disciplinas escolares (bem como do currículo), entendidas 
a partir do "hibridismo" (p.29) discursivo existente nos campos da Educaçáo e da História ao tocarem a referida temática. Ainda nesta mesma primeira parte, poderá o leitor desmantelar uma concepção arraigada nas cristalizaçóes dos unívocos "panos de fundo" históricos, tão recorrentes nas esquematizaçóes contextuais que, por vezes, insistem em apresentar a "realidade domesticada" - tida quase que como uma evidência já sabida (p.62). Em um convite à necessária problematização (p.72), tortuosa e afinada ao enigma, cabe dizer, os autores apresentam os "diferentes presentes", na tentativa de elucidar as distintas possibilidades dentro de um mesmo contexto que, ao fim, revela-se múltiplo, polissêmico, instável, complexo.

Nesse mesmo viés, descortinando o que para além está do oficialmente construído (consensual em essência), encontra-se a análise que, perscrutando a "natureza interna do ensino" (p.12), volta-se à investigaçáo das facetas do trabalho escolar, o qual contornado é por táticas e opinióes resistentes de professores e alunos. Ao perpassar pelos estudos críticos curriculares, reforçando concomitantemente o elo existente com a História da Educação, entende-se o currículo como espaço de luta, resistência e poder, uma "arena" de confrontos entre distintos interesses sociais (p.96).

Em seu turno, a segunda parte do livro, referendada no diálogo entre a historiografia contemporânea e a história do currículo, apresenta-se como lócus privilegiado de análise das categorias "currículo", "disciplina” e "material didático". Em um exercício de desnaturalização das relaçóes existentes entre currículo e ciências de referência, as investigaçóes nesta parte apresentadas corroboram com os debates atuais dos supracitados campos que, como dito, entrecruzam-se.

Dentre os trabalhos apresentados, encontra-se, por exemplo, aquele que, delimitando-se no intervalo entre as décadas de 1960-1980 (em uma escola pública de referência do Rio de Janeiro), aborda a história do espaço institucional analisado com vistas à compreensão da relação entre a seleção 
de docentes e as definições curriculares. $\mathrm{Na}$ investigação, ressalta-se que muitas vezes as referidas definiçóes são frutos mais diretos das relaçóes de poder no espaço engendradas. Estas assumem, pois, um caráter mais significativo que as próprias ciências de referência: "essa divisão de poder entre o professor Carlos Potsch e os coordenadores de Ciências/Biologia [...] ampliou as possibilidades de que algumas das inovaçóes nos anos 1960-70 pudessem ocupar um espaço institucional um pouco diferenciado" (p.175).

Em outra investigação, tendo como foco de análise a própria instituição em que está alocada (UFRJ), mais especificamente restringindo-se ao curso de Pedagogia e ao currículo por este ofertado, um interessante exame se dá sob os olhares de uma autora atenta ao impasse acerca da base identitária do profissional pedagogo, a qual é hoje compreendida a partir da atividade docente. Tal investigação centra-se no campo de disputa existente na instituiçáo entre os anos de 1980 e 1990, em que de um lado estavam aqueles que advogavam a esfera da formação nas "especialidades" e de outro os que ratificavam o discurso que centra a supracitada identidade na docência, esta inclusive avessa à fragmentaçáo e ao caráter tecnicista (vale destacar, conforme postula a autora, que esta última perspectiva de certo modo já se anunciava nos idos de 1940, p.203). Ao abordar esse impasse e, por conseguinte, a promulgação de uma nova proposta curricular da/na Faculdade de Educaçáo, o texto levanta ainda a importância desta na difusão de inovadoras ideias que impulsionariam o debate educativo, inclusive, na década posterior, quais sejam: o caráter de cientificidade da Educação/ Pedagogia; a superação da clássica fragmentação dos conteúdos, dando passos robustos rumo à interdisciplinaridade; e ainda o combate ao discurso que muitas vezes insistia por dissociar teoria e prática.

Por fim, na terceira e última parte, estão reunidos os trabalhos que abordam as variadas atuaçóes e relaçóes, em espaços-tempo também múltiplos, arquitetadas por 
professores, intelectuais e pesquisadores em seus locais de atuação (não desconsiderando, em absoluto, a simbiose entre essas figuras). Eles, concebidos como sujeitos ativos na formulação e disseminação de conhecimentos, destacadamente naqueles circunscritos à sua própria atuação profissional, são tidos como preponderantes intelectuais no que se refere aos processos formativos e identitários.

É o caso, por exemplo, do trabalho que, lançando reflexôes sobre os conceitos de "intelectual" e "geração", entendidos enquanto categorias dotadas de intencionalidades (p.350), volta-se às efetivas contribuiçóes dos variados sujeitos que, de modo reflexivo e criativo, agem nos espaços educativos em que se inserem. Isso a partir do constante exercício de se pensar esses atores em seus respectivos contextos, particularidades e a relação empreendida entre suas produçóes e o pensamento de uma dada época; elementos que devem ser atentamente observados por aqueles que, no contato com as fontes analisadas, intentam o caminho investigativo: "Quando partimos desse tipo de análise seguindo os contextos que os autores delimitaram, abre-se um universo na relação entre o texto e o contexto que muitas vezes não fora observada de modo atento quando realizamos uma determinada pesquisa” (p.348). Cabe destacar que a análise no texto empreendida, embora dialogue com amplas categorias, não desconsidera, por exemplo, os "diferentes presentes" assinalados no primeiro momento da obra, algo perceptível no reportar do autor aos dizeres de Lacapra e Kaplan (1985): “[...] o apelo ao contexto é enganoso, pois nunca se tem um contexto apenas. Temos sim uma série de contextos em interação" (p.347); assinalando dessa forma o coeso eixo que norteia a produção, que, mesmo assim, com destreza garante as singularidades das distintas abordagens apresentadas.

Em uma conversa constante entre o amplo/relacional e as especificidades, embasado pelos discursos da microhistória italiana e atendo-se à cidade cearense de Icapuí, está o trabalho também interessado na profissão docente, mais
Conversas: História do Currículo e da História da Educaçăo
Educ. foco, Juiz de Fora, v. 20, n. 2 , jul. 2015 / out. 2015 
especificamente na figura dos "professores(as) leigos(as)", circunscritos no período entre 1940 e 2000 - apesar de a emancipação do município estudado ocorrer no ano de 1985 , o que demarca o caráter político do trato dado pelo autor ao considerar o território/município enquanto uma "construção social no tempo" (p.287). O particular e o geral, o contexto, as mudanças sociais em suas facetas compreensíveis, as relaçóes de poder localizadas e generalizadas são elementos encarados como importantes ferramentas de pesquisa e estas se fazem presentes na análise que, dentre outras coisas, interessase por saber como a micro-história tem sido incorporada na escrita da História da Educação. É importante ressaltar, em consonância com os estudos que balizaram o texto, que a dimensão local e regional assumem uma "qualificação epistemológica" (p.290). Assim, detectando tensóes, conflitos e discrepâncias que envolviam os professores leigos em sua relação com o Estado, normatizador das condições de trabalho desses profissionais, a investigação centra-se, sobretudo, nas contradiçôes dessa dinâmica social, indo, como em outros trabalhos aqui assinalados, de encontro à "aparente coerência e homogeneidade funcional do contexto social” (p. 292).

Enfim, ainda que reconhecendo as lacunas deste trabalho, tendo em vista, por exemplo, o enfoque dado apenas a alguns dos textos na obra contemplados, cabe dizer que o livro "História do Currículo e História da Educação: interfaces e diálogos", com destreza, alcança o objetivo ao qual se propôs: ultrapassar os limites físicos institucionais ao oferecer à comunidade acadêmica acesso às profícuas discussóes elaboradas pelos grupos de pesquisa do PPGE/ UFRJ nos últimos anos. No ato de inquirir o conhecimento, revelando impasses e incompletudes, especificidades e semelhanças, lançando olhares outros sobre as categorias analíticas, fontes e correntes teórico-metodológicas, o trabalho fornece importantes subsídios para novas interlocuçóes entre os inúmeros pesquisadores dos mais variados centros acadêmicos, estando ou não circunscritos à História da 
Educação e História do Currículo. Afinal, como fica claro a partir do contato da obra, muitos são os entrecruzamentos entre o que nela se apresenta e a educação brasileira nos mais diversos âmbitos.

Data de recebimento: novembro de 2014 Data de aceite: março de 2015 
